\title{
De sociólogo e de louco todo mundo tem um pouco: ou porque a sociologia é a disciplina mais legal da escola
}

\section{Resumo}

Este breve ensaio elabora uma narrativa semi-fenomenológica sobre as possibilidades da sociologia como disciplina no ensino médio, interrogando o lugar e o sentido do artesanato intelectual. Ele é fruto das experiências acumuladas em salas de aula a partir dos diálogos com jovens que perguntam insistentemente sobre a legitimidade, a utilidade e a inteligibilidade do ensino escolar da sociologia. A proposta é insinuar metodologias com potencial de exigir a transformação do próprio saber sociológico, indicando percursos epistemológicos que não estejam ancorados na busca prepotente da "Verdade".

Palavras-chave: Sociologia - estudo e ensino; Ciências Sociais; Prática de ensino.

\section{Fagner Carniel}

Doutor em Sociologia Política pela Universidade Federal de Santa Catarina - UFSC - Brasil fagnercarniel@yahoo.com.br

\section{Lennita Oliveira Ruggi}

Mestre em Sociologia pela Universidade Federal do Paraná UFPR - Brasil

lennitaruggi@hotmail.com

\section{Para citar este artigo:}

CARNIEL, Fagner; RUGGI, Lennita Oliveira. De sociólogo e de louco todo mundo tem um pouco: ou porque a sociologia é a disciplina mais legal da escola. Revista Linhas. Florianópolis, v. 16, n. 30, p. 235 - 247, jan./abr. 2015. 


\title{
Everybody is a little sociologist, just as everybody is a little doctor: or why is sociology the best discipline in school
}

\begin{abstract}
This short essay elaborates a semi-phenomenological narrative about the possibilities of sociology as a high school discipline, questioning the place and meaning of intellectual craft. It is the result of accumulated experiences in classrooms, dialogues with young people who ask repetitive questions about the legitimacy, usefulness and intelligibility of sociology as school teaching. The proposal imply there are methodologies capable of requiring the transformation of sociological knowledge itself, indicating epistemological pathways that are not anchored in the boastful search of "Truth".
\end{abstract}

Keywords: Sociology - study and teaching; Social Science; Teaching practice. 
Também é verdade, de outro modo, que dentre todas as tarefas pedagógicas, a mais difícil é a que consiste em expor problemas científicos de tal forma que um espírito não-preparado, mas bem-dotado, possa compreendê-lo e formar opinião própria - isso, para nós, corresponde ao único êxito absoluto.

Max Weber (2002, p. 31)

\section{Primeiros passos...}

Como é mesmo o nome? - perguntou um aluno no fundo da sala. Sociologia -, escreve timidamente a professora no quadro negro em frente à turma. Que matéria é essa? Reprova? - murmuram dois colegas na primeira fileira. Eu sei, eu sei, a gente vai falar sobre os problemas do mundo, né, professora!? - fala uma menina sentada perto da janela. Meu irmão não teve sociologia na escola, por que é que eu tenho que estudar isso agora? questiona outra. Professora, professora, vai ser muito chato, é... difícil? - mais alguém pergunta. Que saco! - diz outro. Com a folha de presença sobre a mesa, a professora respira fundo e tenta acalmar a turma do $1^{\circ} \mathrm{C}$, Não vai ser chato não, vocês vão gostar, mas antes quero saber o nome de vocês. Então vê um aluno ao lado da porta levantar e dizer: vou ao banheiro...

Não, não é sempre assim, mas muito de nossa "breve" experiência no ensino médio tem mostrado que uma das tarefas mais desafiadoras em sala de aula é apresentar esta disciplina para adolescentes que, em geral, sequer ouviram falar em sociologia'. Afinal, quem sabe o que fazem os sociólogos e sociólogas? Quem são estas pessoas e o que têm a dizer sobre nossa vida? E nós, o que temos a dizer sobre a sociologia? Por onde se começa a ensiná-la? Deste trabalho depende mais do que um bom relacionamento, sensibilização, motivação ou simpatia (também importantes no cotidiano escolar), pois estão sendo abertos os caminhos que levam às primeiras conversas, aos primeiros temas, conteúdos e debates que nos aproximarão de uma leitura sociológica do mundo social. Evidentemente, as páginas que seguem não terão a pretensão de ensinar como se ensina,

\footnotetext{
${ }^{1}$ As dificuldades de legitimação da sociologia no ensino médio não são desconhecidas pelos profissionais da área. Sua história marginal na educação básica brasileira e a parca produção de materiais didáticos e reflexões consistentes sobre o ensino de sociologia configuram um cenário obscuro, incerto e desconfortável, tanto para educadores quanto para educandos.
} 
de apresentar um "bom começo", uma resposta à pergunta - até porque as dinâmicas sociais do conhecimento vêm exigindo da educação mais do que verdades acadêmicas, discursos definitivos, conceitos fixos. O que pretendemos neste texto é oferecer algumas possibilidades metodológicas para abrir as ciências sociais aos alunos da educação básica, deixando-os mergulhar no fazer sociológico e experimentar a construção deste discurso para, quem sabe, começar “imaginar sociologicamente” a própria sociologia.

\section{Sociologia: fazer o quê?}

Nas últimas décadas, nos habituamos a apresentar a sociologia ou o pensamento social através das edificações da ciência - a ciência das sociedades. Falamos de suas origens, tradições e fundadores como quem se agarra em um largo processo de institucionalização para legitimar um ponto de vista, um debate, um conteúdo, uma presença, sua própria presença. Uma história que normalmente remonta os rigorosos processos de (auto)validação de um saber que se consagrou como universal, essencial e verdadeiro; um saber que prometeu romper com algo indesejável, anunciando sua necessária chegada para nos libertar, emancipar, fazer de nós cidadãos críticos e atuantes. Ao menos este é o movimento sugerido pela maioria dos livros e materiais didáticos que circulam pelo país ${ }^{2}$. Contudo, há algo profundamente preconceituoso neste modo de narrar o conhecimento que atenta contra o próprio pensamento sociológico e nos impede de ser a melhor disciplina da escola. Isto porque, quando encarnamos a erudição etnocêntrica e eurocêntrica das tradições sociológicas como a única forma legítima para narrar a vida social, mesmo sem perceber, acabamos superestimando o discurso das ciências sociais e subestimando os saberes e sociabilidades de nossos próprios alunos e alunas ${ }^{3}$ - desrespeitamos aquilo que eles têm a nos oferecer e criamos abismos onde deveríamos "religar saberes" (MORIN, 2002).

\footnotetext{
${ }^{2}$ Alguns dos livros didáticos de sociologia endereçados ao ensino médio com maior circulação no Brasil encaminham sua proposta pedagógica apresentando aos estudantes o saber sociológico como um saber rigoroso, metódico, científico, crítico, refinado, sempre em oposição a certo "senso comum" ingênuo, leigo, alienado, disperso, pouco criterioso. Uma mostra significativa desse gênero didático na produção sociológica pode ser acompanhada a partir da seleção trienal que o Programa Nacional do Livro Didático (PNLD) elabora para a área desde 2012.

${ }^{3}$ Preocupado com o lugar ocupado pelo senso comum na vida cotidiana e na história, José de Souza
} 
Mas como introduzir o pensamento sociológico sem passar pelas amarras da autoridade científica? Como superar a forma pedagógica mitificada pela armadura positivista que coloca esta área do conhecimento acima dos saberes preconceituosamente denominados como "senso comum"? Com efeito, este problema não aceita uma resposta simples, nem definitiva. Refere-se, antes, a uma tarefa artesanal que exige sensibilidade, percepção e imaginação para devolver aos alunos e alunas a condição de protagonistas de sua formação; tornando, assim, as aulas de sociologia um espaço compartilhado de produção de conhecimentos que não se fixe na busca por definições, conceitos, temas estruturais, mas que contribua na conquista de modos de interpretar a realidade social (em suas expressões locais, globais ou virtuais) também a partir da "desconstrução"4 dos enunciados pré-estabelecidos pelas ciências (sociais) modernas. Não podemos novamente perder de vista que o conhecimento produzido pelas ciências está enraizado em relações sociais cotidianas, em modos de ver, perceber e conceber o mundo que estão sempre - e sempre! - sujeitos às dinâmicas da cultura e da linguagem ${ }^{5}$. Por tudo isso, e por tantas outras coisas, julgamos (ética, política e epistemologicamente) não ser mais pertinente apresentar ao ensino médio aquela forma mitificada do saber sociológico, rigidamente protegido pelos muros científicos,

Martins observa que, "na perspectiva erudita, o senso comum é desqualificado porque banal, destituído de verdade, fonte de equívocos e distorções. E com ele o mundo de que faz parte, o da vida cotidiana". Contudo, como pensa o autor, "o senso comum é comum não porque seja banal", mas porque é compartilhado entre os sujeitos da relação social, produzido por eles através de um mesmo "método de produção de significados". Reconhecer isto, ou melhor, enxergar o popular, cotidiano, local, enfim, a sociabilidade das pessoas simples, é a única forma para a sociologia "dar voz ao silêncio, dar vida à História" e se reinventar enquanto conhecimento legítimo (MARTINS, 2008, p. 51-57).

${ }^{4}$ Desconstruir, aqui, consiste em desfazer um sistema de pensamento que se revela dominante, estático, imóvel, para reconstruí-lo em um pensamento que nos empurra para outro lugar: o lugar do "nãoconhecimento" como afirma Jacques Derrida (2005). Nesse sentido, a desconstrução não é um método (uma fórmula) e sim um "acontecimento" (ético, político e epistemológico) que surge do reconhecimento de uma incapacidade. Herdeira da noção heideggeriana de destruktion, a desconstrução se afasta da destruição pura (do encobrimento), pois implica também em reconstrução, em compreender como algo está construído. Portanto, não é o pensamento sobre a realidade escolar que complexifica a herança sociológica, mas é sua própria emergência que "destrói” as respostas estabelecidas e nos obriga a pensar sobre nossas impossibilidades.

${ }^{5}$ Como já observou Pierre Bourdieu, "o sociólogo não pode ignorar que é próprio de seu ponto de vista ser um ponto de vista sobre um ponto de vista. Ele não pode re-produzir o ponto de vista de seu objeto, e constituí-lo como tal, re-situando-o no espaço social, senão a partir deste ponto de vista muito singular (e num sentido muito privilegiado) onde deve se colocar para estar pronto a assumir (em pensamento) todos os pontos de vista possíveis. E é somente à medida em que ele é capaz de se objetivar a si mesmo que pode, ficando no lugar que lhe é inexoravelmente destinado no mundo social, transportar-se em pensamento ao lugar onde se encontra seu objeto (que é também, ao mesmo tempo em certa medida, um alter ego) e tomar assim seu ponto de vista, isto é, compreender que se estivesse, como se diz, no seu lugar, ele seria e pensaria, sem dúvida, como ele" (1997, s/n). 
praticamente intransponíveis para a maioria dos estudantes. Pelo contrário, precisamos encontrar alternativas pedagógicas que permitam aos educadores e educandos adentrar nessa "torre de marfim", para utilizar uma expressão de Immanuel Wallerstein (2001), e perceber os mecanismos de construção do discurso científico, bem como suas lógicas de produção de "Verdade"

A experiência que vivenciamos nos últimos anos e buscamos aqui apresentar remete ao próprio questionamento das ciências sociais, suas tradições, linguagens, mitos e rituais. Parafraseando Bruno Latour (2000), trata-se de oferecer possibilidades para compreender "a sociologia em ação"; ou seja, apresentar e debater em sala de aula o funcionamento desta área do saber para extrair dela os sentidos e significados implícitos ao fazer sociológico. Claro que essa não é a única forma de introduzir a sociologia, certamente não é a mais difundida, mas tem sido o modo mais eficaz que estes educadores encontraram para reequilibrar as relações simbólicas de poder entre os saberes acadêmicos e aqueles insistentemente classificados como senso comum saberes que todos os dias o próprio espaço escolar nos oferece. Apenas desse modo, cremos, será possível que nossos estudantes se sintam parte da constituição do saber sociológico, que o imaginem sociologicamente, reconhecendo a existência de diversos olhares sobre as questões sociais e, sobretudo, percebendo que a interpretação do nosso mundo não é uma tarefa exclusiva de alguns poucos "ilustrados", mas uma atividade permanente de todos nós. Nesse sentido, gostaríamos de dividir com vocês, educadores e educadoras, uma alternativa pedagógica para trabalhar uma pergunta necessária ao início de cada ano letivo: o que é a sociologia afinal?

\footnotetext{
${ }^{6}$ Como argumenta Michel Foucault, "há um combate pela verdade ou, ao menos, em torno da verdade" e isso significa que "não se trata de um combate em favor da verdade, mas em torno do estatuto de verdade e do papel econômico-político que ela desempenha" (1979, p.13).
} 


\section{Sala de aula serve pra quê?}

E se a cada vez que nossos alunos e alunas nos perguntarem o que é sociologia, para que ela serve? - tratássemos de explicar como alguém pode se tornar sociólogo ou socióloga? E se falássemos sobre como se faz sociologia ou sobre como são construídos os discursos sociológicos sobre a realidade? Pode parecer difícil narrar o modos operandi desta área tão pluralizada em distintos cursos superiores, programas de pesquisa e perspectivas teórico-metodológicas; contudo, se nos voltarmos à nossa trajetória acadêmica, nossa formação, certamente iremos (re)encontrar os elementos necessários para trabalhar com constituição da sociologia em sala de aula, com o próprio ethos sociológico ${ }^{7}$. Talvez o modo mais eficaz de fazer isto seja, primeiramente, recuperar os elementos formais de um curso de Ciências Sociais (processos seletivos, disciplinas, provas, trabalhos, diplomas, participação em eventos), para depois retomá-los subjetivamente mostrando suas diversas tradições, hierarquias, disputas, centralidades a ruptura entre licenciatura e bacharelado, a centralidade de alguns autores e conceitos, ou mesmo a hierarquia entre os títulos e centros formadores, podem ser bons pretextos para começar esta atividade. Explicar cabalmente o que é uma monografia, uma dissertação ou uma tese, qual o papel dos orientadores/as, das bancas de qualificação ou defesas de trabalho. Trata-se de um modo de aproximar os estudantes de um universo acadêmico nada homogêneo, unânime ou harmonioso, e convidá-los a vislumbrar um espaço de conflitos e disputas por legitimidade que constituem a própria natureza da atividade sociológica.

Para aprofundar esta discussão é preciso mergulhar nas próprias lógicas de produção do texto sociológico - o resultado final do que fazem os profissionais da sociologia. Um caminho possível para apresentar este processo ao ensino médio é trabalhar com fragmento(s) sociológico(s) que auxilie $(\mathrm{m})$ os estudantes na compreensão das estratégias narrativas que configuram a linguagem científica e acadêmica utilizada por estes especialistas para "explicar" os fenômenos sociais - o "sociologuês".

\footnotetext{
7 Nossa memória pessoal, como já observou Ecléa Bosi (1994, p. 55), se constrói face à própria memória social que nos envolve; "na maior parte das vezes, lembrar não é reviver, mas repensar com imagens e idéias de hoje as experiências do passado", o que significa que as lembranças que dispomos são "construídas pelos materiais que agora estão à nossa disposição no conjunto das representações que povoam nossa consciência atual".
} 
Apresentamos abaixo o trecho inicial da aula inaugural de Émile Durkheim (editada e publicada posteriormente) que, dentre outros tantos textos possíveis, expressa com clareza a condição desta narrativa sociológica:

Eis, senhores, o que a Sociologia se tornou hoje em dia [1887-1888], e essas são as principais etapas de seu desenvolvimento. Os senhores a viram nascer com os economistas, constituir-se com Comte, consolidar-se com Spencer, determinar-se com Schaeffle, especializar-se com os juristas e os economistas alemães; e desse breve resumo de sua história os senhores podem concluir por si sós os progressos que ainda lhe restam por fazer. Ela tem um objeto definido e um método para estudálo. O objeto são os fatos sociais; o método é a observação e a experimentação indireta, em outros termos, o método comparativo. $\mathrm{O}$ que é preciso, agora, é traçar os quadros gerais da ciência e marcar suas divisões essenciais. Esse trabalho não é apenas útil à boa ordem dos estudos; tem um alcance maior. Uma ciência só está verdadeiramente constituída quando se dividiu e subdividiu, quando compreende um certo número de problemas diferentes e solidários uns dos outros. É preciso que ela passe do estado de homogeneidade confusa pelo qual ela começou para uma heterogeneidade distinta e ordenada. (DURKHEIM, 1975, p. 63)

Ao iniciar sua carreira na universidade de Bordeaux, na França, Durkheim foi convidado a dar uma aula inaugural na qual a sociologia (e a ciência em geral) emerge imersa em um movimento histórico aprimorado pela sucessão das gerações de especialistas que a direciona inexoravelmente para o progresso - um modo de pensar o conhecimento científico marcado pela tradição positivista. Remetendo aos autores canônicos do passado, Durkheim lança as bases de sua própria sociologia - uma área do saber com objeto e método pré-determinados, vislumbrando uma perspectiva de futuro calcada na ordem e na especialização. Essencial para a apreciação desta aula introdutória durkheiminiana é retomar a discussão sobre a institucionalização da sociologia, explicitando como a interpretação de um texto depende de maneira estreita de sua contextualização histórico-social. O excerto acima dá ensejo também ao início da demonstração das formas de construção do sociologuês; não sendo uma leitura considerada fácil para estudantes do Ensino Médio, cabe apresentar os significados dos termos método, objeto, fatos sociais e experimentação indireta. Mais do que isso, cabe demonstrar como a sociologia constitui um linguajar próprio, através do qual elabora 
conhecimentos que agregam citações, argumentos e conceitos num ordenamento que se distancia dos saberes não especializados das "pessoas comuns". Em outras palavras, a própria edificação da sociologia, sua forma de existir, é um discurso baseado em si mesmo, nas tradições por ela fundadas ${ }^{8}$. Não é à toa que um texto sociológico exija mais do que começo, meio e fim - ele exige referências bibliográficas.

Explicar o que são as referências bibliográficas é uma atividade desafiadora, pois já estamos tão habituados, tão familiarizados, tão disciplinados por elas, que muitas vezes precisamos nos esforçar para estranhar sua formatação, suas regras estritas e comumente aceitas, suas lógicas de filiação teórica a uma ou outra perspectiva. Todos esses conhecimentos, entretanto, estão implícitos no fazer sociológico e merecem ser apresentados aos estudantes. Com efeito, são diversos os aspectos passíveis de serem aprofundados no tocante às referências bibliográficas. Em primeiro lugar, elas podem ser encaradas como indicadores da persistência de uma perspectiva positivista, à la Durkheim, que toma a história do pensamento sociológico como um processo contínuo que se constrói de geração em geração. Neste sentido, a apresentação das leituras realizadas se prestaria à verificação da continuidade do trabalho disciplinar (especializado) na elaboração de um saber "distinto e ordenado". Por outro lado, as referências têm uma dimensão de honestidade intelectual que passa por reconhecer como as ideias são fruto do diálogo continuado com autores e autoras anteriores - é a partir da leitura (estudo) de textos sociológicos que alguém adquire a maestria no manejo do sociologuês. Assim, ao nos afastarmos do discurso positivista do progresso do conhecimento, poderemos (re)apresentar aos alunos uma dimensão frequentemente obscurecida na versão final dos textos sociológicos - o processo de pesquisa. Isto não significa, evidentemente, que tenhamos que dominar e ensinar os diversos gêneros e estilos de pesquisa para os alunos e alunas do ensino médio, mas a dar menos importância para as conclusões das redações acadêmicas e mais atenção às questões suscitadas antes, durante e depois delas - ressignificando, portanto, o caráter coletivo, portanto social, do empreendimento sociológico.

\footnotetext{
${ }^{8}$ Nesse sentido, a crítica de Boaventura de Sousa Santos (1999, p. 52) às ciências modernas pode nos auxiliar a perceber como a tradição sociológica se legitimou criando critérios de validação e formando seus validadores; afinal, “(...) a razão porque privilegiamos hoje uma forma de conhecimento assente na previsão e no controle dos fenômenos nada tem de científico [Verdadeiro]. É um juízo de valor. A explicação científica dos fenômenos é a auto-justificação da ciência enquanto fenômeno central de nossa contemporaneidade. A ciência é, assim, autobiográfica”.
} 
Ao colocar em pauta o jargão das ciências sociais, também se abre espaço para debater as estratégias de legitimação do poder simbólico nele implícito. Saber escrever e pronunciar nomes de autores e autoras estrangeiras, usar adequadamente os conceitos e temperar o texto com expressões distantes da linguagem oral - estas são estratégias de reivindicação de pertencimento a uma comunidade específica com um conhecimento específico. Tal especificidade é mais do que uma simples diferença, na medida em que revela um processo de exclusão: a sociologia é um saber para iniciados, não se disponibiliza para aqueles imersos no "senso comum". Esta realidade é patente para qualquer um que já tenha tentado trabalhar com os textos "densos" de Max Weber, Pierre Bourdieu ou Florestan Fernandes e ouviu em resposta algo como Eles escrevem em grego, professor? Mas essa dificuldade de interpretação não é exclusiva dos estudantes no Ensino Médio. Uma crônica de Mário Prata, publicada no jornal O Estado de São Paulo, em sete de Agosto de 1998, tem o potencial de problematizar essa questão em sala de aula:

O mais interessante na tese é que, quando nos contam, são maravilhosas, intrigantes. A gente fica curiosa, acompanha o sofrimento do autor, anos a fio. Aí ele publica, te dá uma cópia e é sempre - sempre uma decepção. Em tese. Impossível ler uma tese de cabo a rabo. São chatíssimas. É uma pena que as teses sejam escritas apenas para o julgamento da banca circunspecta, sisuda e compenetrada em si mesma. E nós? Sim, porque os assuntos, já disse, são maravilhosos, cativantes, as pessoas são inteligentíssimas. Temas do arco-da-velha. [...] Orientados e orientandos (que nomes atuais!) são unânimes em afirmar que toda tese tem de ser - tem de ser! - daquele jeito. É pra não entender, mesmo. Tem de ser formatada assim. Que na Sorbonne é assim, que em Coimbra também. Na Sorbonne, desde 1257. Em Coimbra, mais moderna, desde 1290. Em tese (e na prática) são 700 anos de muita tese e pouca prática. [...] Ou seja, o elemento (ou a elementa) passa a vida a estudar um assunto que nos interessa e nada. Pra quê? Pra virar mestre, doutor? E daí? Se ele estudou tanto aquilo, acho impossível que ele não queira que a gente saiba a que conclusões chegou. (PRATA, 1998, s/n)

A partir de uma terminologia e uma construção discursiva muito mais próxima do cotidiano do ensino básico, Mário Prata aborda uma problemática crucial para as ciências sociais contemporâneas, a saber: a quem se destina o conhecimento acadêmico? Deveria ele ficar encerrado em uma banca "circunspecta, sisuda e compenetrada em si mesma"? 
Ora, se é verdade que todos temos acesso a uma dimensão da sociedade, então não deve haver ninguém completamente desprovido de saberes sociológicos. Empreender este diálogo entre as diferentes maneiras de pensar e existir em sociedade é o próprio sentido da disciplina de sociologia nas escolas; um saber que não pode suplantar o senso comum, mas sim se tornar comum, ser compartilhado pelos alunos e alunas, religando os pontos de vista sociológicos com as demais práticas de conhecimento que tecem o cotidiano escolar e social dos estudantes 9 .

\section{A melhor disciplina da escola! Tem prova?}

Não, não tem prova. O que temos é a sensação de que uma abordagem (pedagógica) calcada na apresentação da sociologia como artesanato intelectual (MILLS, 1965), desvelando as etapas acadêmicas e os processos de aprendizagem necessários para o exercício sociológico, pode simultaneamente desmistificar a pretensão de "Verdade" atribuída à ciência e legitimar os conhecimentos das ciências sociais como fruto de trabalhos de pesquisa. Desse modo, pensamos ser possível estabelecer relações com os saberes de "senso comum" que ultrapassem o antagonismo e a contraposição, possibilitando o diálogo.

Mas como elaborar estratégias para democratizar as ciências (sociais)? Como traduzir os textos (e os saberes) da sociologia para que eles possam ser compartilhados, debatidos, contestados? Esta nos parece ser outra questão sugerida pela da crônica de Prata através do contraste entre teoria e prática - para que serve a sociologia afinal? Uma das maiores dificuldades de legitimação da disciplina de sociologia é a ausência de aplicação prática imediata (no sentido estreito que se dá à aplicação, por exemplo, da matemática ou da química). A reflexão sociológica não constrói casas, não produz remédios, não ajuda a calcular impostos - seu campo por excelência é o da teoria. Contudo, quais são as diferenças entre teoria e prática? A acreditar na interpretação histórica e sociológica, esta separação é fruto de uma percepção etnocêntrica, que

\footnotetext{
${ }^{9}$ Romper com o discurso que transformou a ciência em um saber "estranho, distante e incomensurável com a nossa vida", exige uma ação pedagógica que a (re)aproxime do senso comum, "que não falando a língua de todos os dias é capaz de nos comunicar as suas valências e os seus limites, os seus objectivos e o que realiza aquém e além deles" (SANTOS, 1989, p. 11).
} 
acompanha as hierarquias sociais e a divisão social do trabalho: há pessoas destinadas ao labor teórico do pensamento e outras ao batente prático e manual. Todavia, não há teoria sem prática, assim como não há prática sem teoria; como argumenta Foucault (1979, p. 71), “é por isso que a teoria não expressará, não traduzirá, não aplicará uma prática; ela é uma prática”. Portanto, explicar as implicações práticas da teoria (suas representações e preconceitos sociais) é explicar o próprio fazer sociológico, seus sentidos, sua serventia desconstruir o sociologuês, este é um empreendimento eminentemente sociológico

Ora, quando estudantes insistentemente nos perguntam: pra que serve a sociologia? - estão esperando uma resposta clara e categórica que se relacione à finalidade "prática" das ciências sociais. Como explicar que esta questão não tem uma resposta definitiva nem mesmo em sociologuês? A despeito de todos os esforços de Durkheim, o objetivo último da sociologia não é um consenso nem mesmo entre sociólogos e sociólogas. Mas é exatamente o debate suscitado por tal falta de consenso que torna a sociologia um empreendimento tão rico e frutífero. E num caso como esse, o melhor muitas vezes é seguir a boa estratégia socrática e devolver a pergunta: por que o saber deve ter "serventia"? E nas questões que essa interrogação levanta talvez esteja a explicação do porquê a sociologia é a disciplina mais legal da escola.

\section{Referências}

BOSI, Ecléa. Memória e sociedade: lembrança de velhos. São Paulo: Queiroz. 1994.

BOURDIEU, Pierre. A miséria do mundo. Petrópolis: Vozes, 1997.

DERRIDA, Jacques. Pensar a desconstrução. Rio de Janeiro: Estação Liberdade, 2005.

DURKHEIM, Émile. “Aula inaugural do curso de Ciências Sociais - Bordeaux, 1887”. In: CASTRO, Ana Maria \& DIAS, Edmundo Fernandes. (Orgs.). Introdução ao Pensamento Sociológico. Rio de Janeiro: Eldorado, 1975.

FOUCAULT, Michel. Microfísica do poder. Rio de Janeiro: Edições Graal, 1979. 
LATOUR, Bruno. Ciência em ação: como seguir cientistas e engenheiros sociedade a fora. São Paulo: UNESP. 2000.

MARTINS, José de Souza. A sociabilidade do homem simples: cotidiano e história na modernidade anômala. São Paulo: Contexto. 2008.

MILLS, Charles Wrigth. A imaginação sociológica. Rio de Janeiro: Zahar, 1965.

MORIN, Edgar. Religação dos saberes. Rio de Janeiro: Bertreand Brasil. 2002.

PRATA, Mario. Uma tese é uma tese. Jornal O Estado de São Paulo. 7 de Agosto. 1998.

SANTOS, Boaventura de Souza. Introdução a uma ciência pós-moderna. Porto: Afrontamentos. 1989.

SANTOS, Boaventura de Souza. Um discurso sobre as ciências. Porto: Afrontamentos. 1999.

WALLERSTEIN, Immanuel. El etnocentrismo y sus avatares: los dilemas de la ciencia social, in: MIGNOLO, Walter. (Ed.), Capitalismo y geopolítica del conocimiento. Buenos Aires: Ediciones del Siglo, 2001.

WEBER, Max. Ciência e Política: duas vocações. São Paulo: Martin-Claret. 2002.

Recebido em: 28/06/2013 Aprovado em: 29/10/2013

Universidade do Estado de Santa Catarina - UDESC Programa de Pós-Graduação em Educação - PPGE Revista Linhas Volume 16 - Número 30 - Ano 2015 revistalinhas@gmail.com 